\title{
INVESTIGACIÓN
}
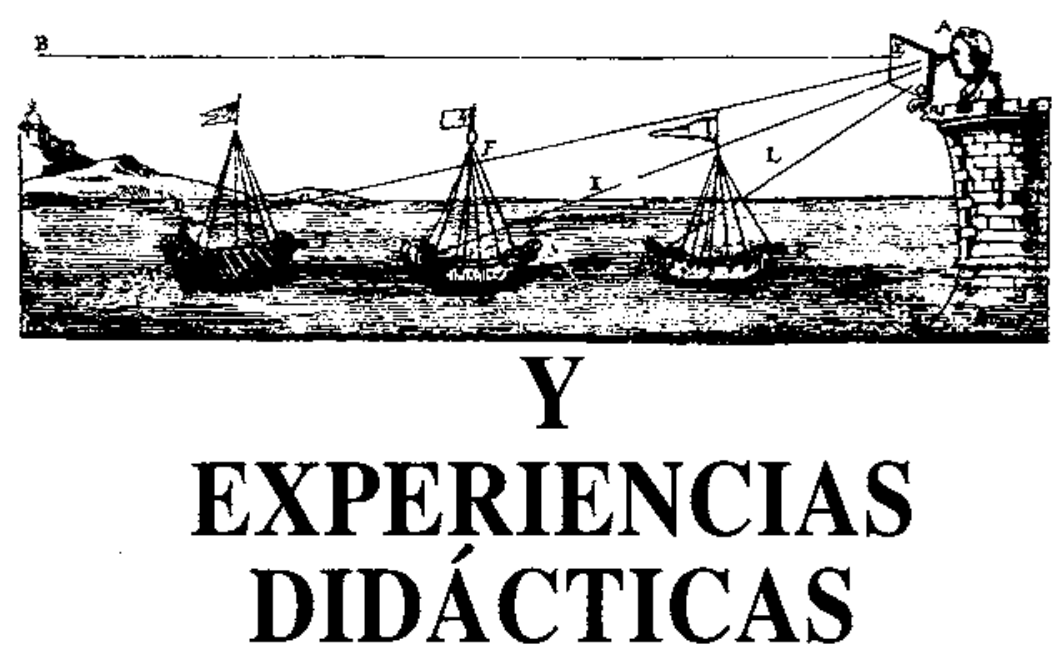

\section{INTRODUCCIÓN A LA GENÉTICA EN LA ENSENANZA SECUNDARIA Y EL BACHILLERATO: II. ¿RESOLUCIÓN DE PROBLEMAS O REALIZACIÓN DE EJERCICIOS?}

\author{
AYUSO, E. ${ }^{1}$, BANET, E. ${ }^{2}$ y ABELLÁN,$T .^{3}$ \\ 1 IB Molina de Segura. Murcia. \\ 2 Facultad de Educación. Universidad de Murcia. \\ 3 Instituto de Enseñanza Secundaria de Bullas. Murcia.
}

\section{SUMMARY}

In this paper we analize the level of knowledge students have at different educational levels (15-18 years), about some basic concepts related to genetic inheritance. The strategies developed by students when solving, successfully, genetic problems have also been studied.

The results show the difficulties in learning through problem-solving activities. Consequently, very often, their posings (even those of cause-effect approach) allow them to find the right solution by applying the correspondent algorithm. As a conclusion, some suggestions to change the students' position on genetic problems are presented. 
Tabla II

Aspectos básicos objeto de las entrevistas.

\begin{tabular}{|c|c|c|}
\hline Conocimiento y aplicación de conceptos & Proceso de resolución & Justificacion del procedimiento \\
\hline Reproducción en las plantas & Conocimiento del algoritmo & Aclaraciones sobre: \\
\hline Relación Genotipo/Fenotipo & & \\
\hline Dominancia/Recesividad & Estrategias utilizadas & ${ }^{*}$ ¿Qué has hecho para averiguario? \\
\hline Homocigosis/Heterocigosis & & \\
\hline Relación Cromosoma-Gen-Alelo & Prediccion de resultados & \\
\hline Cromosomas homblogos & & ${ }^{*}$ ¿Cómo lo sabes? \\
\hline Meiosis y formación de gametos & & \\
\hline Noción de probabilidad & & * ¿Por qué...? \\
\hline
\end{tabular}

requerían la realización de dibujos o esquemas, para facilitar el conocimiento de sus ideas sobre cromosomas, genes...

\section{LOS «PROBLEMAS-EJERCICIO» EN LOS IIBROS DE TEXTO}

Con frecuencia, profesores y profesoras debemos recurrir a los problemas de genética de los libros de texto: a) se trata de ejercicios de lápiz y papel; b) suelen tener un enfoque «causa-efecto»; c) son, en general cerrados, de solución única; $d$ ) muchos de ellos se refieren a seres vivos a veces desconocidos (Dondiego de noche o Mirabilis jalapa) o a características hereditarias difíciles de imaginar (color agutí, alas vestigiales). En consecuencia, no debe sorprendernos que carezcan de interés para los estudiantes de enseñanza secundaria.

La realización del primer ejercicio -que reúne características como las señaladas-muestra que los estudiantes de todos los niveles analizados son buenos resolventes de este caso sencillo (Tabla III), alcanzando la solución con rapidez y seguridad, sin dudar sobre el procedimien- to a seguir, que podría resumirse en los siguientes pasos:

1) Reconocen los símbolos que se emplean habitualmente, identificando el carácter dominante con el alelo representado por la letra mayúscula. Aplican sin dificultad los términos homocigosis/heterocigosis (símbolos iguales/diferentes). En consecuencia, establecen con facilidad el genotipo de los padres.

2. Realizan los cruces combinando las letras según las distintas posibilidades, para obtener la $\mathrm{F}_{\text {, }}$ (los estudiantes de ESO y bachillerato suelen representar esquemáticamente la situación, aunque no se les haya pedido):

P: ¿De dónde proceden estas letras?

Charo: Una del padre y otra de la madre... bueno uno de cada progenitor.

\section{P: ¿Y cómo se llega a esa combinación?}

Charo: Tomando un alelo del padre y otro de la madre por medio de la reproducción sexual.

Tabla III

Resultados relacionados con el caso $\mathrm{A}$

\begin{tabular}{|c|c|c|c|c|c|c|}
\hline \multirow[b]{2}{*}{ Nivel } & \multicolumn{2}{|c|}{ Reproducción en plantas } & \multicolumn{2}{|c|}{ Aplicacion de conceptos } & \multirow{2}{*}{$\begin{array}{l}\text { Representacion } \\
\text { de cromosomas }\end{array}$} & \multirow{2}{*}{$\begin{array}{l}\text { Solución } \\
\text { correcta }\end{array}$} \\
\hline & Sexual & $\begin{array}{l}\text { Forman } \\
\text { gametos }\end{array}$ & $\begin{array}{l}\text { Dominancia/ } \\
\text { Recesividad }\end{array}$ & $\begin{array}{l}\text { Homocigosis/ } \\
\text { Heterocigosis }\end{array}$ & & \\
\hline $4^{\circ} \mathrm{ESO}$ & $6(4)$ & $8(2)$ & $10(-)$ & $10(-)$ & $10(-)$ & 10 \\
\hline $1^{\circ} \mathrm{BAC}$ & $6(4)$ & $9(1)$ & $10(-)$ & $10(-)$ & $7(3)$ & 10 \\
\hline $\mathrm{COU}$ & $2(8)$ & $5(5)$ & $10(-)$ & $10(-)$ & $-(10)$ & 10 \\
\hline
\end{tabular}

* Entre paréntesis el número de casos incorrectos. 
P: ¿Cómo has hecho para averiguar los genotipos de la $\mathrm{F}_{2}$ ?

Charo: He tomado dos progenitores de la $F_{1}$. Cada uno una «A» y una «a»; entonces tienen una descendencia que hemos vuelto a formar tomando un alelo de cada uno.

3) Aunque se han descrito dificultades en la interpretación de conceptos comodominancia y recesividad (Stewart, 1983; Heim, 1991), en nuestro caso se aplican correctamente.

4) Utilizando o no la tabla de Punnett, obtienen las proporciones fenotípicas y genotípicas correspondientes a la $\mathrm{F}_{2}$.

Sin embargo, los resultados no son los mismos cuando se les pregunta por el tipo de reproducción que tienen las plantas o se les pide que representen cromosomas, genes y alelos.

\section{Las plantas y la reproducción sexual}

Como podemos observar en la tabla III, muchos estudiantes de COU afirman que estos seres vivos no tienen reproducción sexual, dudando algunos que puedan formar gametos:

$\mathrm{P:}$ ¿Tienen reproducción sexual las plantas?

Mateo: No, las plantas no tienen reproducción sexual.

$\mathrm{P}:$ ¿Cómo se reproducen?

Mateo: Con reproducción asexual y... no recuerdo to otro.

P: $¿$ Qué significa la $x$ (signo de multiplicar) que pones entre las plantas de tallo largo y las de tallo corto.

Mateo: El cruce entre las dos...

P: Cuando hablas de cruce ¿a qué te refieres?

Mateo: La verdad es que en las plantas no sabría explicarlo... En animales sería reproducción, en las plantas no lo sé.

El mismo alumno confirma, después, esta idea al responder lo siguiente:

\section{P: ¿Los vegetales forman gametos?}

Mateo: No.

P: Y un animal, ¿los forma?

Mateo: Sí. Un animal sí porque tiene reproducción sexual.

En otros casos, se muestran desconcertados cuando se pide que justifiquen sus explicaciones, reflejo de un vacío conceptual importante y síntoma evidente de que no relacionan la reproducción de las plantas con la realización de este ejercicio:

P: Pero ¿cómo el padre AA «manda» (palabra utilizada por la alumna) el alelo A?

Adoración: Esto va en un gen. Los alelos forman parte de un gen... Cuando se cruzan...

P: ¿Qué significa que «se cruzan»?

Adoración: Que se ponen los cromosomas... No lo sé.

P: ¿Tienen las plantas reproducción sexual?

Adoración: Sí.

$\mathrm{P}: ¿$ Sabes cómo se realiza?

Adoración: No... Bueno hay algunas que tienen esporas, pero las esporas eran de reproducción asexual en los helechos... y otras...

P: Imagina que no estuviéramos hablando de una planta, que se tratara de un ratón ¿ cómo pasaría de padres a hijos la información?

Adoración: Por las células sexuales.

Estas circunstancias son preocupantes si se tiene en cuenta que en COU la selección se realizó en función de sus calificaciones. Sin embargo, estas dificultades no impiden la resolución correcta, en todos los casos, de este sencillo ejercicio.

Aunque nuestra intervención didáctica se proponía establecer relaciones explícitas entre el proceso de reproducción de los seres vivos -incluyendo la meiosis-y los mecanismos de transmisión de las características hereditarias, en ESO y en bachillerato encontramos dificultades similares, aun cuando Ios resultados son más satisfactorios: algunos estudiantes no atribuyen a las plantas reproducción sexual (propia de Ios animales o, en algunos casos, sólo de las personas), pero admiten la posibilidad de que puedan formar gametos. Ello pone de manifiesto la persistencia de esta idea y aconseja no dar por supuestos ciertos conocimientos -incluso aquellos que parecen más elementales-y la necesidad de indagar sobre ias ideas de los estudiantes para detectar las dificultades que pueden tener en este tipo de tareas.

2. ¿Cómo representan los estudiantes los cromosomas, genes y alelos?

Algunos autores han puesto de manifiesto que los estudiantes cometen errores al situar los genes en los cromosomas (Allen y Moll, 1986; Kindfield, 1994). En nuestro caso, cuando pedíamos a los estudiantes de COU que dibujaran, como ejemplo, una célula con seis cromosomas y situaran en el lugar correspondiente los genes responsables de la longitud del tallo, la mayoría de ellos se sorprendían y confesaban no haber hecho esto con 
anterioridad. No obstante, todos ellos acometieron la tarea. Los dibujos realizados muestran:

a) Confusión entre cromátidas y cromosomas homólogos:

P: ¿Podrías dibujar una célula con seis cromosomas?

Ana: (Dibuja los cromosomas con dos cromátidas, figura 1 , esquema «a»).

P: ¿En qué zona está la información sobre el tipo de tallo?

Ana: Por ejemplo aquí. (Marca en una de las dos cromátidas la letra «A»).

P: ¿Y en el otro brazo?

Ana: En el caso de «Aa»... (Marca en la otra cromátida y a la misma altura una «a»).

b) Dificultades para establecer relaciones entre el material genético de ambas cromátidas:

$P: ¿$ Qué significa este dibujo? (figura l, esquema «b», dibujado por la alumna).

Adoración: Esto sería una pareja de cromosomas homólogos. El punto es la parte de ese cromosoma que determina ese carácter.

P: ¿Qué significan los dos segmentos? (las dos cromátidas del cromosoma).

Adoración: Un cromosoma está formado por dos cromátidas.

P: Entonces en una cromátida está la información «A», ¿y en la otra?

Adoración: Ya no hay más información sobre el color de ojos.

En los otros dos niveles, se observa en todos los casos el esquema «c» (Fig. 1), que se corresponde con el utilizado con frecuencia en el desarrollo de nuestra propuesta, si bien en $1^{\circ}$ de bachillerato tres alumnas sitúan los alelos en todos los cromosomas (esquema «d»). Para ellas todos los cromosomas de una célula llevan la misma información genética:

P: ¿Por qué pones «A» o «a» en todos los cromosomas?

Laura: Todos los cromosomas son iguales..., Ilevan Ia misma información.

P: En las personas, por ejemplo, el gen para el carácter "color de ojos" ¿estaría en los 46 cromosomas?

Laura: Sí... y sólo se refleja en el organo dónde toque dar su función.
Parece evidente que en genética, como ocurre en otras áreas científicas, el conocimiento del algoritmo es, en muchos casos, imprescindible. Además, como señala Stewart (1988), a pesar de las connotaciones peyorativas de este término, su utilización es necesaria para contrastar hipótesis y tiene cierto potencial para promover el aprendizaje de conceptos. Para ello, sin embargo, los estudiantes deben ser conscientes de la situación a la que intentan encontrar solución, y de las razones por las cuales to aplican. Nuestros resultados ponen de manifiesto que los estudiantes se pueden desenvolver de forma adecuada ante ejercicios de esta naturaleza, utilizando planteamientos de partida equivocados o confusos. Ejemplos como el presentado no pueden ser considerados como verdaderos problemas; se trata más bien de «ejercicios», que -como señalan Allen y Moll (1986)animan a una ineficiente aproximación algorítmica; es decir, se pueden resolver con éxito aplicando, sin razonar, unas reglas conocidas (ejercitando un truco), que se identifican con procedimientos utilizados en situaciones anteriores análogas (García Cruz, 1990).

Como hemos mostrado, la búsqueda de la solución no fomenta, necesariamente, aprendizajes de tipo conceptual sobre la herencia biológica; tampoco contribuye al desarrollo de un pensamiento hipotético-deductivo, por medio del cual los alumnos aprendan a resolver verdaderos problemas; y mucho menos dan una visión de la ciencia como una actividad intelectual, aspectos señalados por Stewart (1988) como consecuencias educativas importantes para las actividades de esta naturaleza.

\section{LOS PROBLEMAS EFECTO-CAUSA}

Como respuesta a esta situación, muchos profesores han considerado necesario modificar el enfoque de estas actividades, de manera que, respondiendo mejor a las características de verdaderos problemas, su resolución implique comprender su naturaleza, analizar los datos y valorar los resultados obtenidos. Como ya hemos señalado, algunos autores han destacado las ventajas de plantear problemas que vayan de los efectos (fenotipos observables) a las causas (genotipos y modelos de herencia). De esta forma, los estudiantes se ponen en una situación de trabajo semejante a las que analizan los científicos (Johnson y Stewart, 1990). En nuestro trabajo hemos formulado dos problemas efecto-causa (casos B y C), aunque sólo en el segundo de ellos no conocen el modelo de herencia. Los resultados obtenidos (Tabla IV) muestran cómo casi todos Ios estudiantes resuelven bien ambas situaciones. Sólo en COU se pueden apreciar algunas dificultades aI respecto.

Los razonamientos utilizados por los estudiantes para resolver el problema B no difieren, básicamente, de los empleados en el primer caso; es decir, partir de los fenotipos, conociendo el modelo de herencia, no les supone dificultades adicionales, ni les incita a reflexionar sobre la situación planteada. Sin embargo, en lo que se refiere al tercer problema, hemos podido comprobar la puesta en práctica de dos estrategias diferentes: 
1) Ensayo-error: a) Se asigna la dominancia -a modo de tentativa - a uno de los dos caracteres y se prueba si se produce la correspondencia adecuada entre fenotipos y genotipos; $b$ ) así, sin un razonamiento explícito, los estudiantes resuelven bien el problema, utilizando Ias consecuencias de los conceptos de dominancia/recesividad, homocigosis/heterocigosis y separando correctamente las letras por las que se representan estos caracteres.

2) Análisis de fenotipos: a) Utilizando sus conocimientos sobre genética, analizan el pedigrí que presenta el problema, centrándose rápidamente en la familia situada en la parte izquierda. Al ser un ejemplo sencillo, extraen inmediatamente la conclusión de que no podría aparecer un individuo homocigótico recesivo, sin que sus progenitores fueran heterocigóticos (realmente no llegan a formular una hipótesis). Aunque comprueban que del cruce de la derecha se pueden deducir las dos posibilidades, concluyen señalando, de forma correcta, cuál es el carácter dominante y el recesivo; b) a partir de aquí, reconstruyen los genotipos de todos los individuos representados en el pedigrí.

La primera de las estrategias señalađas predomina en los tres niveles educativos. Sólo recurren a la segunda cuando el entrevistador les pregunta: ¿Podría ser dominante el otro carácter?

P: (En el tercer problema). ¿Cuál es el carácter dominante?

Antonio: Poseer pelos.

P: ¿Por qué lo sabes? ¿Podría ser dominante el otro carácter?

Antonio: Porque si fuese recesivo, los dos progenitores (de la familia de la izquierda) debían ser homocigóticos «aa» y entonces los dos hijos debían ser también homocigóticos aa, pero aparece uno que tiene pelos y uno que no los tiene.

\section{P: ¿Y si sólo conocieses la segunda familia?}

Antonio: Aquí podría ser dominante y recesivo.

P: Pero ¿sigues pensando lo mismo sobre cuál es el carácter dominante?

Antonio: Sí, teniendo en cuenta la primera familia, concluyo que sí es dominante poseer pelo.

Esta característica distingue a los novatos de los expertos en relación con la resolución de problemas de genética. A diferencia de los primeros, los segundos hacen uso de sus conocimientos sobre la herencia para analizar la situación. A partir de ellos formulan hipótesis, confirman resultados... (Simmons, 1987; Stewart y Van Kirk, 1990). Finalizada esta primera parte, todos los estudiantes predicen, de manera correcta, en relación con el tercer apartado del problema.

Aunque el tercer problema podría fomentar la aplicación de estrategias más coherentes con el trabajo científico -en particular si se complica algo más su planteamientoéstas no son indispensables para resolverlo correctamente; tampoco es necesario para ello comprender los conceptos implicados (Tabla IV). En unos casos la definición de los conceptos pueden hacernos creer que conocen su significado, aunque no sea así (cromosomas homólogos); otras veces, su aplicación algoritmica puede ser adecuada, aunque no se comprendan correctamente (relaciones gen-alelo); en otras ocasiones los alumnos y alumnas adquieren nociones incompletas, que limitan el significado de algunos procesos importantes (meiosis).

\section{Cromosomas homólogos}

A muchos estudiantes les resulta relativamente fácil evocar -aun con explicaciones sencillas, como la que se presenta a continuación- alguna de sus características:

Tabia IV

Resultados relacionados con los casos B y C.

\begin{tabular}{|c|c|c|c|c|c|}
\hline \multirow{2}{*}{ Nivel } & Cromosomas homólogos & Relaciones gen-alelo & \multicolumn{2}{|c|}{ Meiosis } & \multicolumn{2}{|c|}{ Solución correcta } \\
\cline { 3 - 6 } & & & & \multicolumn{2}{|c|}{ Caso B } \\
\hline $4^{\circ} \mathrm{ESO}$ & $9(1)$ & $9(1)$ & $9(1)^{*}$ & $10(-)$ & $10(-)$ \\
\hline $1^{\circ} \mathrm{BAC}$ & $8(2)$ & $10(-)$ & $8(2)^{*}$ & $10(-)$ & $10(-)$ \\
\hline COU & $-(10)$ & $-(10)$ & $-(10)^{*}$ & $9(1)$ & $8(2)$ \\
\hline
\end{tabular}

* Todos afirman que consiste en una reducción del número de cromosomas. 
P: ¿Has oído hablar de cromosomas homólogos? ¿Qué significado tiene?

Mariano: Por ejemplo, en el ser humano si tiene 46 cromosomas y los divides en parejas son 23 y 23 . De esos 23 , coges uno y del otro grupo de los 23 coges otro y son las parejas de homólogos.

\section{P: ¿Qué relación tienen entre sí?}

Mariano: Son iguales... el mismo tamaño...

Sin embargo, resulta más difícil relacionarlos con la resolución de problemas, ya que -además de ser confundidos con cromátidas, como vimos antes (Fig. 1 «a»)estas definiciones no implican que se alcance a comprender su significado, como ponen de manifiesto las explicaciones y los dibujos de Pedro y Mariano, alumnos de COU (Fig. $2\langle a » y \ll b »)$ :

(El alumno dibuja el esquema de una célula de Laura con seis cromosomas, sólo en uno de ellos ha marcado la información para el color de ojos).

P: ¿En este esquema habría otro cromosoma que lleve también información para el color de ojos?

Pedro: ¿Para el color de ojos? Creo que no.

P: Dibuja un esquema de los cromosomas de una célula y su información para el color de ojos.

Mariano: (El alumno dibuja dos cromosomas homólogos, marcando en cada uno de ellos una zona en la que señala $(O O »)$.

Estos resultados muestran las dificultades para interpretar que los alelos para el mismo gen se encuentran en los cromosomas homologos. Incluso cuando no se les indica el número, algunos estudiantes dibujan dentro del circulo un número impar de cromosomas. La enseñanza ha producido, en este caso, un aprendizaje superficial del concepto, con tendencia al olvido, que refleja relaciones muy confusas o equivocadas en relación con este aspecto, sin que esto dificulte una correcta aplicación del algoritmo.

Sin embargo, los resultados obtenidos en $4^{\circ}$ de ESO y $1^{\circ}$ de bachillerato pueden ser considerados como muy satisfactorios. Utilizando como referencia los esquemas realizados en clase, la mayoría de alumnos y alumnas dibujan un número par de cromosomas, los agrupan por parejas y representan un alelo en cada uno de ellos (Fig. 1 "c»).

\section{Significado de gen y alelo}

Evidentemente, cabría esperar que cuando los estudiantes resuelven bien problemas como éstos, la aplicación de conceptos tan básicos, como gen y alelo, debería ser consecuencia de que se comprende el significado de ambos términos. Sin embargo, los resultados de las entrevistas ponen de manifiesto que en $\mathrm{COU}$ esto no es así:

1) En unos casos se trata de conceptos distintos, aunque muy parecidos:

P: ... ¿Y qué es un alelo?

Pedro: El alelo es... una de las partes que controla una de las características que se heredan... un trozo de cromosoma..., se puede decir que es el que lieva la información necesaria.

P: ¿Es lo mismo gen que alelo?

Pedro: ¿Gen? Creo que por definición es la unidad mínima con información suficiente para sintetizar una proteína.

P: ¿Y cómo lo relacionas con alelo?

Pedro: Son parte también de cromosomas... Serán de unas características parecidas, casi iguales.

2) Para otros, los alelos son como partes de los genes:

P: ¿Qué significa alelo?

Antonio: Si un gen es lo que define un carácter, el alelo sería... como otra subdivisión de ese carácter, por ejemplo, el pelo va a ser un carácter y el color del pelo lo dicta el alelo, bien sea rubio, moreno...

Esta confusión se refuerza por expresiones utilizadas por profesores y libros de texto (Radford y Bird-Stewart, 1982; Pearson y Hughes, 1988), como, por ejemplo, "gen (y no alelo) letal».

La mayoría de las definiciones de los estudiantes de $1^{\circ}$ de bachillerato y $4^{\circ}$ de ESO reflejan -aun con ciertas imprecisiones- que estos conceptos se han aplicado con cierto conocimiento de su significado: sus explicaciones consideran a los alelos como variedades de un gen. Sin duda, el establecimiento de relaciones explícitas en nuestra intervención entre características hereditarias-cromosomas. genes y alelos, utilizando como apoyo las representaciones gráficas, pueden haber contribuido a esta situación:

\section{P: ¿Cómo relacionas gen y cromosoma?}

Salvadora: Un cromosoma está formado por un conjunto de genes y éstos son los que determinan cada una de las características de ese ser.

P: ¿Gen y alelo es to mismo?

Salvadora: No; por ejemplo, gen tiene que ver con alguna característica, y el alelo es el que determina si es recesivo o si es dominante.

P: ¿Cómo relacionas cromosomas, gen y alelo? 
Marcos: El cromosoma contiene los genes y las diferentes clases de genes son los alelos.

\section{Meiosis y formación de gametos}

Como hemos dicho antes, diversos autores han puesto de manifiesto las dificultades para comprender el proceso de meiosis y, en particular, su relación con la tabia de Punnett y con todo este baile de letras mayúsculas y minúsculas de los problemas (Liberatore Cavallo y Schafer, 1994). En este sentido, en COU hemos observado lo siguiente:

1) Aunque se reconoce que en este proceso se forman gametos con la mitad del número de cromosomas, esto no significa que lo entiendan como la separación de cromosomas homólogos:

\section{P: ¿En qué consiste la meiosis?}

Juan: A partir de una célula madre... primero se reducen los cromosomas a la mitad...

P: ¿Qué significa «reducir los cromosomas a la mitad»?

Juan: Sí, se parten... Los cromosomas que llevan las características para lo mismo se parten... se dividen y forman dos células que tienen información necesaria para todas las características del ser humano, pero pueden ser diferentes entre sí... entonces, a partir de ahí, se produce una mitosis y se vuelven a formar, a partir de una célula madre diploide, cuatro células hapioides.

2) Como consecuencia de la confusión entre cromosomas homólogos y cromátidas, algunos estudiantes piensan que durante la meiosis se separan las cromátidas:

El alumno dibuja un cromosoma con dos cromátidas, en una marca una zona y escribe «O», en la otra marca otra zona a la misma altura y escribe «0». Al dibujar un gameto representa un cromosoma con una sola cromátida y con su alelo.

P: ¿Eso que has dibujado, qué es?

Pedro: Medio cromosoma. Cuando se dividen los cromosomas... pero no sé cómo se llama... ¿cromátida?... es que como se llama no lo sế.

3) También existen dificultades para relacionar adecuadamente la formación de gametos con meiosis (Stewart, 1982). Hemos podido comprobar cómo, en general, la formación de gametos se relaciona con las representaciones que realizaban en la figura 1:

- Como se considera un proceso de reducción a la mitad del número de cromosomas, algunos de los estudiantes

Figura 1

Representación de cromosomas, genes y alelos.

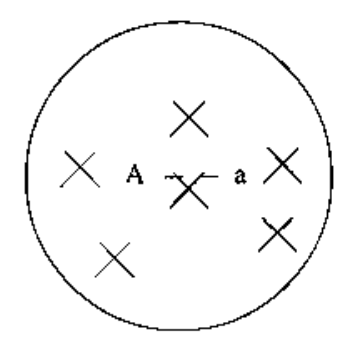

a) Confusión cromosoma homólogo/cromátida.
Dibujos representativos de COU

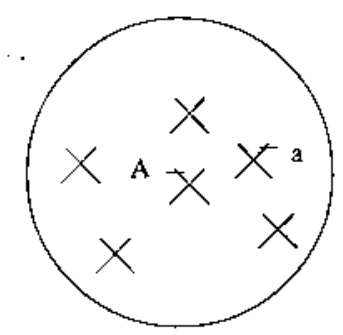

b) Ausencia de correspondencia de genes en cromátidas.

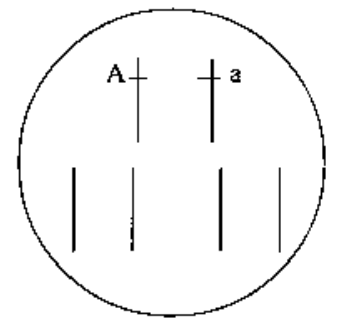

c) Los atelos se sitúan en los cromosomas homólogos.

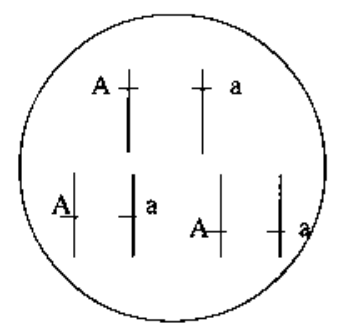

d) Todos los cromosomas son iguales. 
de COU que habían utilizado el esquema «a» de la figura I tienen dificultades para obtener los dos gametos, ya que, separando uno a uno los cromosomas, no pueden explicar cómo se pueden distribuir los dos alelos (figura 2 «c»):

\section{P. ¿Cómo serían los gametos de Laura?}

Mateo: Tendrían tres cromosomas, la mitad.

P. Y para el carácter color de ojos, ¿qué información llevaría cada uno?

Mateo: Pues no sé... Sé que las células sexuales tendrían la mitad de los cromosomas, pero no sé cómo poner los genes.

- En otros casos, sin embargo, no tienen problemas para formarlos (Fig. 2 «d»):

P: ¿Podrías decir cómo serían los espermatozoides de Luis?

Pedro: Serían iguales (que las células de partida) pero haploides, con la mitad de cromosomas?

P: ¿Podrías dibujarlos?

Pedro: Llevaría la mitad de los cromosomas y en uno de sus cromosomas presentaría sólo un alelo referente al color de ojos.

Creemos necesario abordar la meiosis y los procesos de formación de gametos en el contexto de la herencia biológica (en COU se incluyen en la división celular). Así lo hicimos y los resultados obtenidos en $1^{\circ}$ de bachillerato y $4^{\circ}$ de ESO ponen de manifiesto lo acertado de esta decisión. Prácticamente todos los estudiantes de estos niveles educativos coinciden en señalar que los gametos se forman en el proceso de meiosis, que contienen un cromosoma de cada pareja de homólogos y relacionan meiosis - aunque de forma elemental-con los problemas que están resolviendo. Además, al utilizar esquemas como el «c» de la figura 1, no tenían problemas para formar los gametos (esquema «e», figura 2).

P: (Segundo problema) ¿Qué gametos podrían formar Laura y Luis respecto al color de ojos?

SaIvadora: Laura, en el $100 \%$ de los casos, sus gametos serían con el alelo «o», el recesivo, y Luis tendría un $50 \%$ de probabilidades para fabricar gametos con el aielo «O», que es el dominante, ojos oscuros, y $50 \%$ de probabilidad para formar gametos con el alelo «o».

p: ¿Por qué en los gametos dibujas la mitad de cromosomas?

Figura 2

Cromosomas homólogos y formación de gametos.

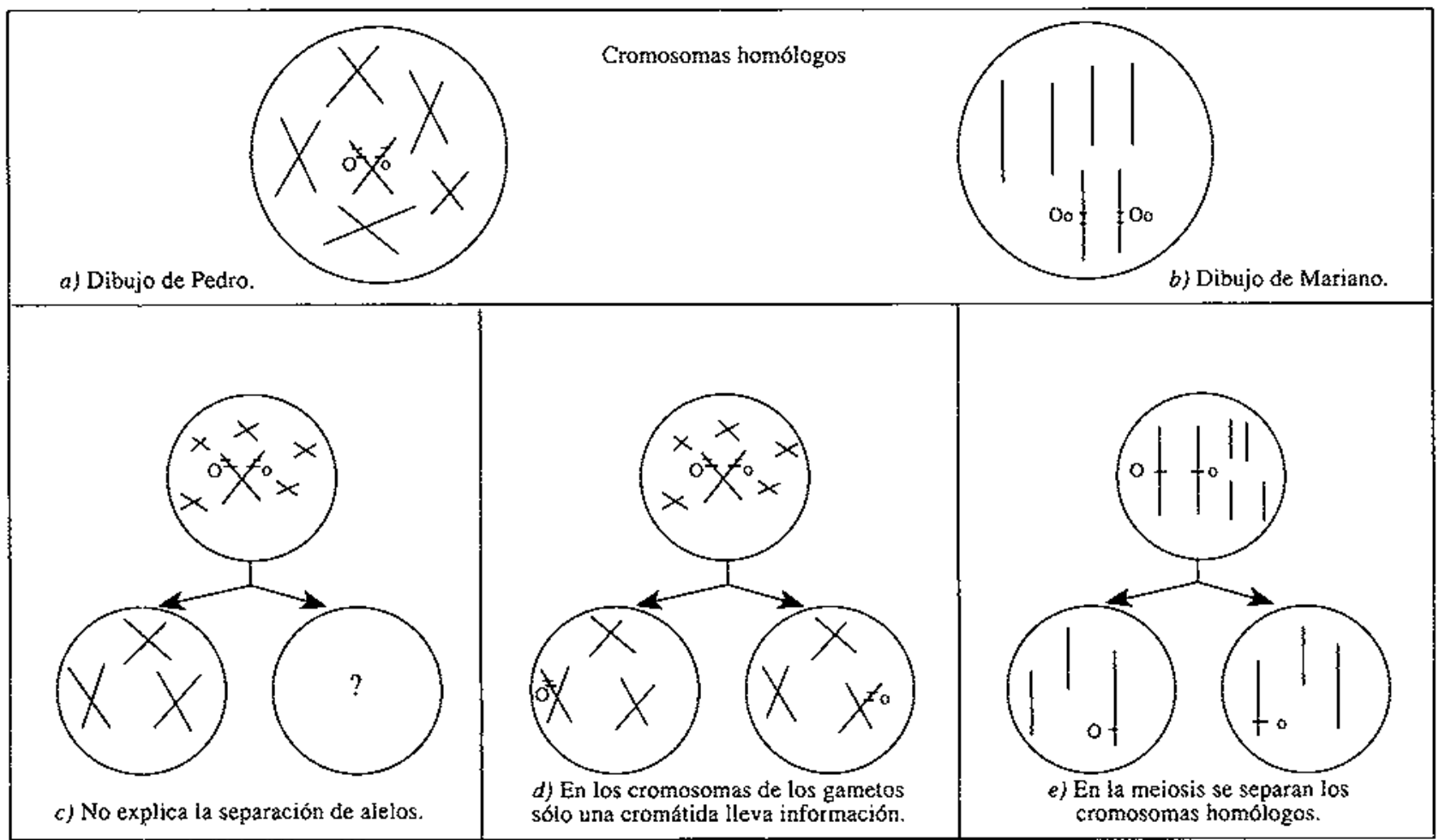


Salvadora: Los gametos tienen siempre la mitad de cromosomas que las demás células y de cada par de cromosomas, al dividirse en dos, cogería un cromosoma del par, que iría a un gameto, y el otro cromosoma pasaría al otro gameto.

\section{Noción de probabilidad}

Este concepto es difícil de comprender para los estudiantes de estos niveles educativos. En consecuencia, algunos autores señalan que se deberia evitar plantear problemas en los que las dificultades derivadas de la noción de probabiliđad impidan su resolución, utilizándose en su lugar la tabla de Punnett (Thomson y Stewart, 1985; Smith y Suther Sims, 1992).

Aunque compartimos este criterio y, en consecuencia, así lo hemos tenido en cuenta en nuestra intervención en. las atlas de enseñanza secundaria, las entrevistas sobre las tres actividades hacían referencia a esta idea al preguntar sobre la distribución de la descendencia y las posibilidades que tendrían cada uno de los fenotipos y genotipos resultantes de los cruces. Los resultados obtenidos pusieron de manifiesto lo siguiente:

1) Sólo un alumno de $1^{\circ}$ de bachillerato mantiene un criterio relativamente adecuado sobre este concepto:

P: (En relación con el segundo problema) ¿Qué tipos de descendencia puede tener ese matrimonio para el color de ojos?

Alfonso: Ojos claros y ojos oscuros... con el $50 \%$ de probabilidad en cada caso.

P: Si tienen dos niños, ¿uno sería de ojos claros y otro de ojos oscuros?

\section{Alfonso: No tiente por qué ser así.}

P: ¿Y si tuvieran 10 ?

Alfonso: No, tampoco tiene por qué ser así.

P: Entonces por qué dices que tiene una probabilidad de un $50 \%$ de cada tipo?

Alfonso: Si se dieran muchos casos, sí puede darse la posibilidad de que la mitad fuese de ojos oscuros y la mitad claros.

P: ${ }_{\iota}$ Pero diez no es mucha descendencia para la especie humana?

Alfonso: Son muchos, pero para poder comprobar eso se necesitan muchísimos más hijos.

2) En ocasiones se afirma que todos los gametos se producirían de forma simultánea, de manera que el número de descendientes estaría determinado por las combinaciones resultantes de aplicar la rabla de Punnett:
P: (En el primer problema) ¿Podrías decirnos cuántos descendientes van a haber en este cruce («Aa» $x$ «Aa»)?

Juan: Cuatro descendientes.

P: ¿Y cómo sería cada uno?

Juan: ¿Cómo serían? ¿Los cuatro? Serían tres de tailo largo y uno de tallo corto.

3) En otros casos se tiene una idea determinista de las proporciones, muchas veces fomentada por la clase de problemas que aparecen en los libros de texto (Jiménez, 1994):

P: (En el primer problema) ¿Qué significa 1/4 «AA», $2 / 4$ «Aa»y $1 / 4$ «aa»?

Antonio: Sobre una descendencia de 4, serian las posibles combinaciones existentes: saldria $1 / 4$ homocigótico dominante, $2 / 4$ de heterocigóticos, y $1 / 4$ de homocigótico recesivo.

P: Por ejemplo, si tienen 100 descendientes, ¿cómo serían?

Antonio: Sobre 100, serían 25 «AA», 50 «Aa» y 25 homocigóticos recesivos.

4) A veces se aplica bien pero no se comprende por qué se hace:

Mateo: (En el tercer problema) Los hijos serian un $50 \%$ sin pelos, homocigóticos y un $50 \%$ con pelos, heterocigóticos.

P: ¿Te sorprendería que tuvieran cuatro hijos, todos con pelo?

Mateo: No.

p: Entonces ¿por qué crees que se dan estos porcentajes?

Mateo: No sé... La verdad es que yo los ejercicios de genética los hago de esta forma y...la verdad es que no sé por qué se dan estos porcentajes.

e) Por último, algunos alumnos y alumnas de ESO y bachillerato piensan que la probabilidad es la misma para cada tuno de los fenotipos, con independencia del número de casos en el que éstos se pudieran producir:

P: (En el primer problema, al determinar las proporciones de $\left.l a F_{2}\right)_{\text {¿Cuál crees que es más probable? }}$

Ana: ¿El más probable? Pues están todos al $50 \%$.

P: Pero... hay tres casos.

Ana: Sí, bueno el más probable es el «Aa».

P: ¿Por qué?

Ana: No sé... están todos por igual. 


\section{LA PODEROSA FUERZA DEL ALGORITMO}

Cuando planteamos estas tres situaciones, to hicimos pensando encontrar diferencias en relación con el éxito en su resolución. Esperábamos que el primer caso fuera resuelto con facilidad, atm cuando los estudiantes no hubieran comprendido alguno de los conceptos que estaban siendo aplicados. Por el contrario, para la realización de los dos restantes -en particular el tercero-, sería necesario haberlos aprendido de una manera significativa.

Nuestra sorpresa ha sido comprobar que esto no era así. Aunque estos resultados son limitados, nos parecen suficientes para poner de manifiesto cómo el dominio del algoritmo -que requiere poco más que conocer los trucos para utilizar las letras y manejar algunos términos sencillos de aplicar, como dominancia/recesividad (mayúsculas/minúsculas) y homocigosis/heterocigosis (iguales/diferentes) - es suficiente para resolver con éxito también los problemas efecto-cansa. Creo que podríamos llegar a afirmar que cualquier persona que conociera estas reglas -aunque no tuviera formación específica sobre genética- también podría encontrar la solución correcta para este tipo de problemas.

En otras palabras, como señala Stewart (1983), resolver correctamente los problemas no significa, necesariamente, que se pongan en práctica los conocimientos adecuados. Por ello, en muchos casos, en lugar de propiciar la reestructuración o la aplicación de conocimientos sobre la herencia biológica, se tiende a mecanizar Ia resolución de los mismos. De esta manera se anula, o al menos se limita bastante, su eficacia para aprender a partir de ellos (Mondelo, García y Martínez, 1988). Esto se traduce en la práctica, en una renuncia a abordar los problemas de genética como pequeñas tareas de investigación, en las que, entre otros aspectos, fuera necesario comprender el sentido real de la tarea, formular hipótesis, planificar y desarrollar el trabajo, interpretar Ios resultados obtenidos o elaborar conclusiones. Es decir, muchas veces presentamos estas situaciones como noproblemas (GiI et aI., 1988).

\section{ALGUNAS SUGERENCIAS PARA REORIENTAR LOS PROBLEMAS DE GENETICA}

Creemos que es posible modificar esta tendencia para que los problemas de genética cumplan una doble función (Collins y Stewart, 1989; Stewart y Van Kirk, 1990): a) contribuir a que los estudiantes comprendan mejor la estructura conceptual de la genética, mediante la puesta en práctica de conceptos fundamentales sobre la herencia biológica; b) ejercitar a Ios alumnos y alumnas en Ios aspectos básicos del trabajo científico (ensayo de hipótesis, tratamiento de datos, interpretación de resultados ...), que contribuya a comprender la naturaleza de la ciencia como una actividad intelectual.
Para ello, debemos señalar lo siguiente:

1) Aunque el enfoque causa-efecto puede utilizarse para iniciar a los estudiantes en la resolución de problemas de genética -ya que de esta manera pueden entender fácilmente las relaciones entre conceptos básicos (dominancia/recesividad, genotipo/fenotipo...) y pueden aprender el algoritmo correspondiente- es también necesario formular verdaderos problemas: es decir, situaciones que impliquen analizar los datos, emitir hipótesis explicativas, cierta planificación del trabajo, interpretación de los resuitados obtenidos... De esta manera se evitará la manipulación inmediata de los datos -procedimiento que no responde a los principios de una metodología científica- y los planteamientos cerrados, que tienen como actividad fundamental la ejercitación del algoritmo. En este tipo de problemas, el diseño experimental y la realización de experimentos se deberían sustituir por la búsqueda de las estrategias de resolución adecuadas en el cuerpo de conocimientos teóricos en el que se enmarca el problema (Jiménez, Albaladejo y Caamaño, 1992).

2) En la medida de lo posible, deberíamos comenzar por situaciones sencillas, procurando que el objeto del problema tenga interés para los estudiantes (sobre genética humana, por ejemplo), y propiciar que, en la medida de lo posible, fueran ellos los que recogieran los datos del problema, más que proporcionárselos en el enunciado. Además, deberían centrarse sobre los conceptos formales más importantes, buscando estrategias para hacerlos comprensibles a los alumnos (Smith y Suthern Sims, 1992).

3) Aunque es cierto que los planteamientos efectocausa, en particular cuando no se conoce el modelo de herencia, suelen implicar un mayor razonamiento, en ocasiones, como hemos tenido ocasión de comprobar, este cambio resulta claramente insuficiente. A medida que los estudiantes adquieran mayor experiencia sobre estos contenidos, su formulación debería hacerse más compleja, presentando problemas divergentes -con posibilidad de más de una solución- para favorecer que los alumnos y alumnas deduzcan la información básica e importante del mismo (Moll y Allen, 1987) y se propicie la emisión de hipótesis alternativas.

4) Para clarificar las relaciones entre conceptos, nos parece muy importante conocer las ideas de los estudiantes sobre los aspectos básicos relacionados con la herencia biológica y utilizar esquemas -o maquetas, como recomienda Pashley (1994)-para la resolución de estos problemas. A través de ellos, se pueden representar las relaciones entre cromosomas, genes y alelos, y su comportamiento durante la meiosis. Además, nuestros resultados coinciden con los de Moll y Allen (1987) cuando afirman que se obtienen mejores resultados si el método de resolución está basado en la meiosis y no en el uso de un algoritmo. Sin embargo, es necesario precisar que nos referimos a aquellos aspectos más destacados de este proceso - que en la enseñanza secundaria se reduciría prácticamente a la formación de gametos-, dejando para cursos superiores alguno de sus detalles. 
5) Habitualmente, se plantean los problemas al final de la lección (aplicación y refuerzo de Ios conocimientos aprendidos). Estando de acuerdo con esta utilización, es necesario destacar su gran utilidad en otras fases del proceso de enseñanza: a) si el contenido suscita interés y puede ser abordado sin excesivas dificultades, puede servir para motivar a los estudiantes y hacer explicitas sus ideas sobre la herencia biológica; $b$ ) si además su planteamiento es adecuado, constituyen actividades excelentes para reestructurar los conocimientos y una manera efectiva de aprender, ya que plantean una concepción dinámica del aprendizaje basada en la comprensión y en la acción (Stewart, 1988). En cualquiera de estas situaciones, sería necesario considerar las ventajas que puede representar el trabajo en grupo para afrontar este tipo de actividades, lo que puede conferirles la perspectiva social y compartida que caracteriza el trabajo científico. El papel del profesor debería situarse en un plano diferente al habitual, colaborando con los estudiantes para ayodarles a encontrar solución a la situación planteada.

6) Por útimo, en ocasiones es necesario cuestionar los criterios de considerar que los estudiantes han aprendido cuando tienen éxito y logran alcanzar la solución adecuada. Así, de acuerdo con Stewart y Dale (1989), debemos tener en cuenta otras alternativas posibles para evaluar la resolución de cada problema, de forma que no sólo «miremos» la respuesta, sino también el modelo

\section{REFERENCIAS BIBLIOGRÁFICAS}

ALLEN, R. y MOLL, M. (1986). A realistic approach to teaching Mendelian Genetics. The American Biology Teacher, $48(4)$, pp. $227-230$.

BANET, E. y AYUSO, E. (1995). Introducción a la genética en la enseñanza secundaria y bachillerato: I. Contenidos de enseñanza y conocimientos de los alumnos. Enseñanza de las Ciencias, 13(2), pp. 137-153.

BROWN, C.R. (1990). Some misconceptions in meiosis shown by students responding to an advanced level practical examination question in Biology. Journal of Biological Education, 24 (3), pp. 182-185.

BROWNING, M. E. y LEHMAN, J. D. (1988). Identification of student misconceptions in genetics problem solving via computer program. Journal of Research in Science Teaching, $25(9)$, pp.747-761.

CHO, H., KAHLE, J.B. y NORDLAND, F.H. (1985). An investigation of high school Biology textbooks as sources of misconceptions and difficulties in genetics and some suggestions for teaching genetics. Science Education, $69(5)$, pp. 707-719

COLLINS, A. y STEWART, J. (1989). The knowledge structure of Mendelian Genetics. The American Biology Teacher, 51(3), pp. 143-149.

GARCÍA CRUZ, C.M. (1990). Algunos errores conceptuales sobre genética derivados de los libros de texto. Enseñanza de las Ciencias, 8(2), pp. 197-198. que la explica, poniendo el énfasis sobre el proceso y sus dificultades, más que en el producto (Stewart y Hafner, 1991).

Es evidente que no siempre es posible trasladar a nuestras aulas estas referencias. En particular, se nos presentan dificuitades importantes cuando queremos plantear los problemas como pequeñas tareas de investigación, aunque en algunos casos se intenta solucionar -con distinto éxito- mediante la utilización de programas informáticos (Jungck y Calley, 1985; Peard, 1983; Stewart, Streibel y Collins, 1987; Stewart y Maclin, 1990). No obstante, estas consideraciones -que constituyen aspectos fundamentales de nuestra propuesta didáctica sobre herencia biológica y evolución en aulas de enseñanza secundaria- han determinado los resultados que hemos obtenido en este trabajo, incluso a pesar del tiempo transcurrido. Por ello-aunque consideramos necesario profundizar en nuestro estudio-, creemos que es posible dar un salto cualitativamente importante en el tipo de problemas de genética que planteamos a nuestros alumnos y alumnas en clase, de manera que los estudiantes pueden ser capaces de resolverlos, comprendiendo los conceptos que aplican y aprendiendo - simultáneamente- a solucionar situaciones problemáticas, que contribuirán a que se formen ideas más adecuadas sobre la ciencia y ia forma de trabajo de los científicos.
GIL, D., DUMAS, A., CAILLOT, M., MARTÍNEZ TORREGROSA, J. y RAMÍREZ, L. (1988). La resolución de problemas de lápiz y papel como actividad de investigación. Investigación en la Escuela, 6, pp. 3-20.

HACKLING, M.W. y TREAGUST, D. (1984). Research data necessary for meaningful review of grade ten high school Genetics curricula. Journal of Research in Science Teaching, 21(2), pp. 197-209.

HEIM, W.G. (1991). What is a recessive allele? The American Biology Teacher, 53(2), pp. 94-97.

HODSON, D. (1990). A critical look at practical work in school science. School Science Review, 71(256), pp. 33-40.

JMÉNEZ, M.P. (1994). Teaching Evolution and Natural Selection: A Look at Textbooks and Teachers. Journal of Research in Science Teaching, 31(5), pp. 519-535.

JIMÉNEZ, M.P., ALBALADEJO, C. y CAAMAÑO, A. (1992). Didáctica de las ciencias de la naturaleza. Madrid: MEC.

JOHNSON, S.K. y STEWART, J. (1990). Using philosophy of science in curriculum development: An example from high school genetics. International Journal of Science Education, 12(3), pp. 297-307.

JUNGCK, J.R. y CALLEY, J.N. (1985). Strategic simulations and Post-Socratic pedagogy: Constructing software to develop long term inference through experimental inquiry. The American Biology Teacher, 47(1), pp. 11-15. 
KINDFIELD, A.C.H. (1994). Understanding a basic biological process: Expert and novice models of meiosis. Science Education, 78(3), pp. 255-283.

KINNEAR, J. (1983). Identification of misconceptions in genetics and the use of computer simulations in their correction. Proceedings of the International Seminar on Misconceptions and educational strategies in Science and Mathematics, Nueva York: Cornell University, Ithaca.

LIBERATORE CAVALLO, A.M. y SCHAFER, L.E. (1994). Relationships between students' meaningful learning orientation and their understanding of genetics topics. Journal of Research in Science Teaching, 31(4), pp. 394-418.

MITCHELL, A. y LAWSON, A.E. (1988). Predicting genetics achievement in nonmajors college Biology. Journal of Research in Science Teaching, 25(1), pp. 23-27.

MURRAY,D. y BOWBAL, D. (1987). Constructing a conceptual framework for solving a problem. Proceedings of the second international seminar: misconceptions and educational strategies in Science and Mathematics, pp. 348-359. Nueva York: Cornell University, Ithaca.

MOLL, M. y ALLEN, R. (1987). Student difficulties with Mendelian Genetics problems. The American Biology Teacher, 49(4), pp. 229-233.

MONDELO, M., GARCÍA, S. y MARTÍNEZ, M.C. (1988). Genética y resolución de problemas: Aspectos didácticos. IX Encuentros de Didáctica de las Ciencias Experimentales. Tarragona.

PASHLEY, M. (1994). A-level students: Their problems with gene and allele. Journal of Biological Education, 28(2), pp. 120-126.

PEARD, T. (1983). The Microcomputer in cognitive development. Proceedings of the International Seminar on Misconceptions and educational strategies in Science and Mathematics. Nueva York: Cornell University, Ithaca.

PEARSON, J.T. y HUGHES, W.J. (1988). Problems with the use of terminology in Genetics Education: 2. Some examples from published materials and suggestions for rectifying the problem, Journal of Biological Education, 22(4), pp. 267274.

RADFORD, A. y BIRD-STEWART, I.A. (1982). Teaching genetics in schools. Journal of Biological Education, 16(3), pp. $177-180$.

SIMMONS, P. (1987). Misconceptions of experts and novices during a genetics computer simulation, en Novak, J.D., Proceedings of the second international seminar: misconceptions and educational strategies in Science and Mathematics, pp. 447-451. Nueva York: Cornell University, Ithaca.

SLACK, S. y STEWART, J. (1990). High school students" problem solving performance on realistic genetics problem. Journal of Research in Science Teaching, 27(1), pp. 55-67.
SMITH, M. y GOOD, R. (1984). Problem solving and classical genetics: Successful versus unsuccessful performance. Journal of Research in Science Teaching, 21(9), pp. 895-912.

SMITH, M.U. (1988). Successful and unsuccessful problem solving in classical Genetic Pedigrees. Journal of Research in Science Teaching, 25(6), pp. 411-433.

SMITH, M.U. y SUTHERN SIMS, O. (1992). Cognitive development, genetics problem solving, and genetics instruction: A critical review. Journal of Research in Science Teaching, 29(7), pp. 701-713.

STEWART, J., (1982). Difficulties experienced by high school students when learning basic Mendelian genetics. The American Biology Teacher, 44(2), pp. 80-84.

STEWART, J. (1983). Student problem solving in high school Genetics. Science Education, 67(4), pp. \$23-540.

STEWART, J. (1988). Potential learning outcomes from solving genetics problems: A typology of problems. Science Education, $72(2)$, pp. 237-254

STEWART, J. y DALE, M. (1989). High school students' understanding of chromosome-gene behavior during meiosis. Science Education, 73(4), pp. 501-521.

STEWART, J. y HAFNER, R. (1991). Extending the conception of «problem» in problem solving research. Science Education, 75(1), pp. 105-120.

STEWART, J. y MACLIN, R. (1990). Representing genotype to phenotype mappings. Journal of Biological Education, 24(2), pp. 113-116.

STEWART, I. y VAN KIRK, J. (1990). Understanding and problem-solving in classical genetics. International Journal of Science Education, 12(5), pp. 575-588.

STEWART, J., HAFNER, B. y DALE, M. (1990). Students' alternative views of Meiosis. The American Biology Teacher, $52(4)$, pp. 228-232.

STEWART, I, STREIBEL, M. y COLLINS,A. (1987). Computers as tutors: "MENDEL» as an example, en Novak, I.D., Proceedings of the second international seminar: misconceptions and educational strategies in Science and Mathematics, pp. 477-489. Nueva York: Cornell University, Ithaca.

TOLMAN, R. (1982). Difficulties in Genetic Problem Solving. The American Biology Teacher, 44(9), pp. 525- 527.

THOMSON, N. y STEWART, I., 1985. Secondary School genetics instruction: Making problem solving explicit and meaningful. Journal of Biological Education, 19(1), pp. 5362.

WALKER, R.A., HENDRIX, J.R. y MERTENS, T.R. (1980). Sequenced instruction in genetics and piagetian cognitive developmemt. The American Biology Teacher, 42(2), pp. 104-108. 


\section{ANEXO I}

\section{Problemas de genética planteados}

\section{Caso A:}

En las plantas, el alelo «A» determina el carácter tallo largo, mientras que el alelo «a», determina el carácter talio corto.

Se cruza una planta homocigótica de tallo largo, con una planta homocigótica de tallo corto. Responde a las siguientes cuestiones:

a) ¿Cuál será el genotipo y el fenotipo de la descendencia de ese cruce $\left(F_{i}\right)$ ?

b) Si cruzáramos dos plantas de esa descendencia (de la $F_{i}$ ) ¿cuál sería el genotipo y el fenotipo de la descendencia de éstas $\left(F_{z}\right)$ ?

\section{Caso B:}

En los seres humanos, el carácter de ojos oscuros domina sobre carácter de ojos claros. Hemos investigado el color de ojos en una familia, de la que te mostramos el siguiente árbol genealógico:

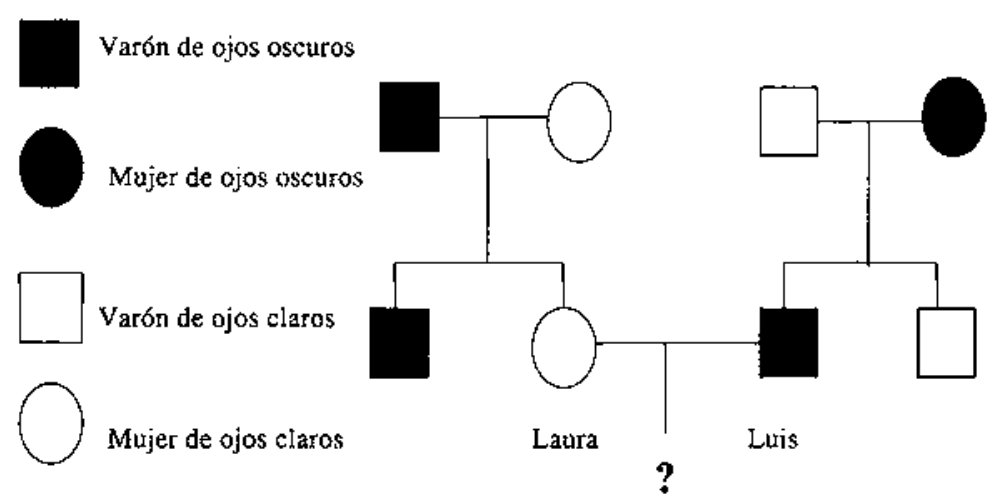

A partir de estos datos:

a) Señala el genotipo de todos los miembros de la familia.

b) ¿Cómo será para ese carácter el próximo hijo que esperan Luis y Laura?

\section{Caso C:}

La presencia de pelos en la segundo falange de los dedos es un carácter hereditario en la especie humana. Hemos investigado si se poseen pelos o no en una familia, de la que te presentamos el siguiente árbol genealógico:
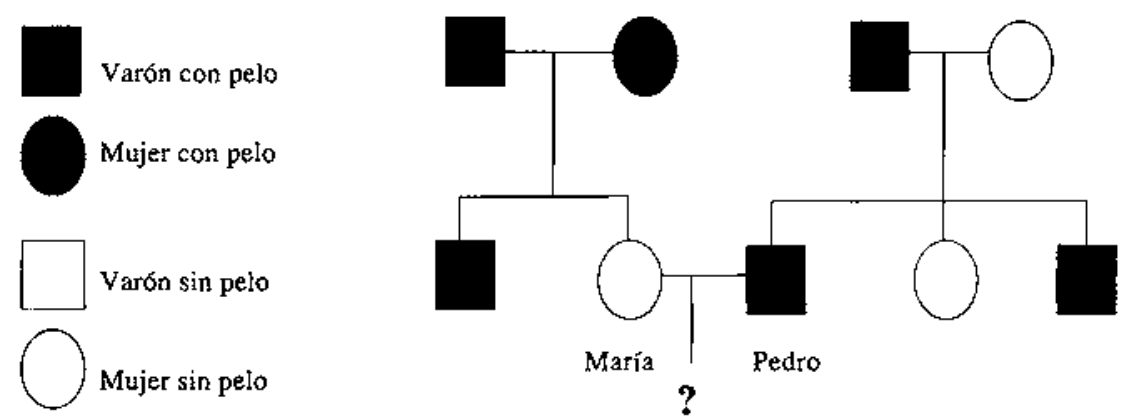

a) ¿Cuál es el carácter dominante: poseer pelos o no poseer pelos?

b) Señala el genotipo de todos los miembros de esta familia.

c) ¿Cómo será para este carácter el próximo hijo que esperan María y Pedro? ¿Por qué? 


\section{ANEXO II \\ Contenidos de la entrevista}

Las entrevistas se han Hlevado a cabo tomando como referencia los contenidos que presentamos a continuacion, aunque las preguntas no siempre se han ajustado a esta formulación, ni se han planteado en este orden, ya que su desarrollo ha sido flexible, adaptándose a la dinámica de la interacción entrevistador-estudiante.

\section{Parte primera (Caso A):}

1) ¿Cuál es el genotipo de las plantas progenitoras?

2) ¿Cuál es el genotipo y el fenotipo de la $F_{1}$ ? Qué has hecho para averiguarlo?

3) ¿Cómo se transmite la información hereditaria a los descendientes de la $F_{1}$ ?

4) ¿Tienen reproducción sexual las plantas? ¿Forman gametos?

5) Representa en un esquema (un círculo) una célula de una de las plantas (sólo con seis cromosomas). Indica los genes que lleva para cada uno de los fenotipos?

6) Indica el genotipo y el fenotipo de la $\mathrm{F}_{2}$. ¿Cómo lo has averiguado? ¿Cuál es el genotipo más probable en la $\mathrm{F}_{2}$ ? ¿Cómo lo sabes? ¿Cuántos descendientes podrían haber en la $\mathrm{F}_{2}$ ?

\section{Parte segunda (Caso B):}

1) ¿Qué símbolos utilizas para representar los distintos genotipos? ¿Cuáles son los genotipos posibles? ¿Qué fenotipos corresponden a cada genotipo?

2) Señala los genotipos de todos los familiares. Justifica los resultados.

3) Dibuja una célula de Laura (representa sólo seis cromosomas). ¿Conoces el significado del término «cromosomas homólogos»?

4) Dibuja una célula de Luis (sólo con seis cromosomas). Sitúa los genes que lleva para ese carácter. ¿Qué representa cada símbolo que has dibujado? ¿Qué relación existe entre cromosoma, gen y alelo? Justifica tu respuesta.

5) ¿Qué tipos de espermatozoides podría formar Luis para este carácter? ¿Qué tipos de óvulos podría formar Laura para este carácter? Dibújalos.

6) ¿Qué tipos de hijos, para este carácter, podrían tener Laura y Luis ¿por qué?

7) ¿Qué es más probable para Laura y Luis, tener un hijo de ojos oscuros o de ojos claros? ¿Por qué?

\section{Parte tercera (Caso C):}

1) ¿Cuál es el carácter dominante? ¿Podría ser el otro? Justifica tu respuesta.

2) Señala los genotipos de todos los familiares. ¿Cuáles son los genotipos de Pedro y Marfa? ¿Por qué?

3) Dibuja urta célúla de Pedro (representa sólo 6 cromosomas). Sitúa los genes que lleva para ese carácter. ¿Qué representa cada símbolo que has dibujado?

4) ¿En qué consiste la meiosis?

5) ¿Qué tipos de espermatozoides podría formar Pedro para ese carácter? ¿Qué ovulos podría formar María? ¿Qué información llevarían cada uno de los gametos para el color de ojos? Dibújalos.

6) ¿Cuántos descendientes tendrán Peơro y María? ¿Cómo serían sus hijos para este carácter? ¿Con qué probabilidad? 